\title{
Mobile Learning: A Systematic Review
}

\author{
Slah Al Saleh, Ph.D \\ King Saud University \\ Saudi Arabia
}

\author{
Sameer Ahmad Bhat \\ King Saud University \\ Saudi Arabia
}

\begin{abstract}
In the recent years, exploring the use of mobile technology to support learning is the key challenge for educators and instructional designers. However, there is little literature that examines the dimensions of mobile learning domain for both the researchers and instructional designers, and focuses on the effective use of the latest mobile learning technologies for education. This study takes a systematic approach to review the literature and provides a more comprehensive analysis and synthesis of articles from the year 2003 to year 2014. Findings in this study reveal that most highly-cited articles are found to focus on the evaluations of mobile learning systems and their design. Experimental methods are found to be the primary research methods for the evaluation of m-learning systems. PDAs, handhelds are currently the most widely used devices for mobile learning but these are expected to be replaced by emerging technologies. The results of this study may provide comprehension for researchers and educators into research trends in mobile learning.
\end{abstract}

\section{Keywords}

Mobile and Personal Devices, Tablet PCs, Multitouch Devices, Collaborative Learning Tools.

\section{INTRODUCTION}

Mobile technologies today are a part of our daily lives. People are connected with various mobile technologies, providing them access to a wider variety of information sources and serving as a global means of communication. With the rapid innovation in mobile technologies, their implementation in teaching and learning process is gaining wider acceptance at global level. The support provided by the emerging mobile technologies allows fast information exchange and processing. The efficiency of these innovations significantly increases the level of freedom for work and study, permitting anywhere anytime learning environment. Educators are in search for exploiting the unique abilities and features of these mobile technologies to create new and efficient forms of learning.

This study first provides a literature review on the mobile learning domain. Next it examines the trends in m-learning by systematically analyzing the previous studies. Then it explores new emerging practices relating to the use of mobile technologies. Finally at the end is given a conclusion presenting the findings of this systematic review.

\section{LITERATURE REVIEW}

\subsection{What is Mobile Learning?}

Mobile learning or m-learning has been defined as learning that takes place via wireless devices such as mobile phones, personal digital assistants (PDAs), other hand held devices or laptop computers. According to Sharples "learning is mobile in terms of space, i.e. it happens at the workplace, at home, and at places of leisure; it is mobile between different areas of life, i.e. it may relate to work demands, self-improvement, or leisure; and it is mobile with respect to time, i.e. it happens at different times during the day, on working days or on weekends" [1]. Mobile technologies are now a days capable of supporting learning practices in both blended and standalone contexts. Thus as a new model for learning, it has become an emerging field of research and development activities [2]. The field is now getting to be more prepared for supporting excellent learning practices and learners are progressively requesting more incredible portability and adaptability.

\subsection{Motivation from the Previous Reviews}

The literature review covers many papers from highly cited authors. After analyzing the papers, it was found that most of the previous reviews focused on the number of articles published, selected year, authors, learning platforms, research sample groups, designing learning environments. It was observed that most studies showed the focus on social learning, formal and informal learning, learners' engagement, evaluation and assessment of learners', learners' attitude toward mobile and ubiquitous learning.

For the current interest in mobile learning, various theories have been proposed. Only a smaller number of studies have focused on the design of framework and the mobile devices technologies compatible for m-learning systems. When compared to the state-of-the-art mobile learning systems, these are found to be incomplete from several aspects. For example Dulev viewpoint suggests that there is a need for appropriate management of courses, preparation of self-study educational materials, and design of educational modules, which are accessible at various devices [3]. Mobile phones and PDAs are the most commonly used devices for mobile learning, but these may be replaced in the future by new emerging technologies [4]. A critical review by Karen Melhuish of iPads supporting learning, that draws on learning theory suggests that the device may offer an exciting platform for consuming and creating, content in a collaborative, interactive way [5].

\subsection{Future Research Directions}

The most successful developed education systems make use of learning theories and are evaluated with a huge amount of empirical evidence for their effectiveness. With the surveys and experimental methods as the preferred research methodologies, previous studies have mostly focused on the effectiveness and the design for m-learning systems [4]. For example, Gwo-Jen Hwang evaluated the effectiveness of mobile learning environment by conducting experiment on a local culture course for southern Taiwan students. The experimental results showed that the proposed approach promoted the students' learning interest and attitude, and also improved their learning achievement [6]. The study by ShuSheng Liaw et al. in which 152 participants used the mlearning system, shows that enhancing learners' satisfaction, encouraging learners' autonomy, empowering system functions, and enriching interaction and communication activities have a significant positive influence on the acceptance of m-learning systems [7]. 
Utilizing the ubiquitous computing method, u-learning has been built into a learning context. U-learning is an advanced form of simple mobile learning in which learning environments can be accessed in various contexts and situations. [8]. Various frameworks have been proposed to meet the demands of the ubiquitous learning environments. For example, G.D Bormida made ubiquitous access to knowledge for user including mobile workers and learning citizens through Open Mobile Access Abstract Framework (OMAF) using the web based delivery. [9]. The m-learning activities employ learners in the learning process significantly, resulting in an effective system with higher level improvement in communication and learning. Thus there is demand for the design and implementation of efficient $\mathrm{m}$ learning systems in most learning environments today. Over the next 10 years it expected that the personal, portable, wirelessly networked technologies will become ubiquitous in the lives of learners[10]. In this study the focus is on the research prominence of mobile and ubiquitous learning by a systematic-analysis, for examining the trends in mobile learning studies to provide a more comprehensive analysis of previous studies.

\section{Systematic Review and Analysis}

This study is based on systematic analysis conducted on searched articles from databases which include Elsevier, IEEE Xplore and Wiley online library. By searching for keywords "Mobile learning" or "Ubiquitous learning", "Effect of mlearning" generated a set of more 100 articles. The inclusion/exclusion criteria were defined to include and exclude the studies out of those 100 articles.

\subsection{Inclusion / Exclusion Criteria}

For the selection of the studies, out of the total 100 highly cited articles searched, was based on the framed criteria, as a part of the systematic review process. Only those articles were selected that met the inclusion. Table 1 lists the inclusion/exclusion criteria.

\subsection{Data sources and Coding}

Article search was made from e-databases which Elsevier, IEEE Xplore and Wiley online library. Next the duplicate results were minimized. Only 13 articles where selected for the review that met the inclusion criteria specified in table 1 .

\subsection{Data coding and Analysis}

Coding process for assessing the quality of the journals was based on the 13 codes set by the coders. The inter-coder agreement for coding was $98.6 \%$. The codes include Publication Date, Title, Study purpose, Place of study, Learners' Level, Type of Study, Number of Participants, Mobile device type, Issues Reported, Courses, Educational contexts, Learning Outcome, Citations.

\section{RESULTS}

A total count of 100 articles on mobile learning design and implementation in various contexts, from the year 2003 to 2014 were collected and only 13 were selected that met the inclusion criteria. Fig -1 illustrates the analysis performed on the occurrence of publications since 2003 to 2014. The statistics of the figure indicate that frequency of publication on mobile learning is highest from IEEE followed by Elsevier and the others. (Note the figure statistics indicate the average rate of articles published since 2003 to 2014).

\subsection{M-learning: Research purposes, Methodologies and Outcomes?}

The systematic review of articles produced several

TABLE 1

Inclusion criteria

\begin{tabular}{|c|c|}
\hline a. & $\begin{array}{l}\text { Implements mobile leaming in an } \\
\text { educational system }\end{array}$ \\
\hline b. & $\begin{array}{l}\text { Uses research methodologies- experiment, } \\
\text { survey, or mixed method }\end{array}$ \\
\hline c. & $\begin{array}{l}\text { Includes participants from any level of } \\
\text { education }\end{array}$ \\
\hline $\mathrm{d}$. & Accesses and Evaluates m-leaming system \\
\hline e. & Reports current mobile technological trends \\
\hline f. & $\begin{array}{l}\text { Reports content delivery methods for m- } \\
\text { leaming }\end{array}$ \\
\hline g. & $\begin{array}{l}\text { Addresses leamers attitude towards mobile } \\
\text { technology }\end{array}$ \\
\hline h. & Reports Network access methods \\
\hline i. & Institutional Support for mobile devices \\
\hline $\mathrm{j}$. & Published between 2003 to 2014 \\
\hline & 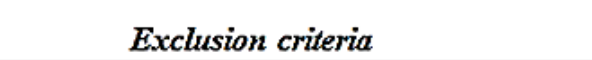 \\
\hline
\end{tabular}

a. Does not implement mobile leaming

b. Does not provide a framework

c. Does not evaluate device performance

d. Does not address mobile technological issues

e. If other than joumal articles

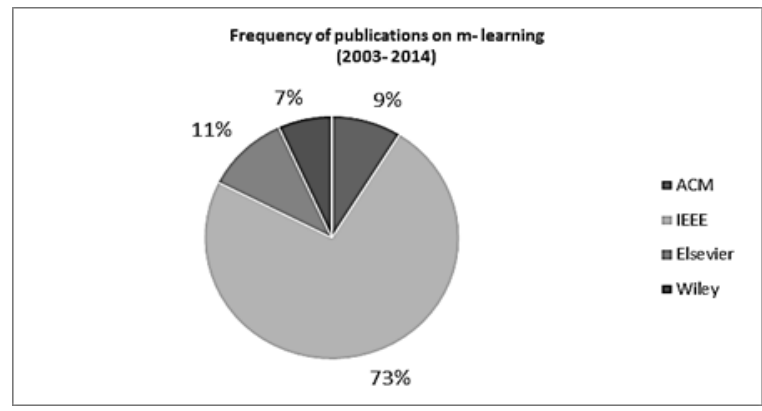

Fig 1- Frequency of publications on m-learning (2003-2014) 
classifications for m-learning.

\subsubsection{Research purposes}

Designing frameworks for m-learning and scaffolding aids, assessing the learners' knowledge of mobile devices, defining the characteristics of mobile devices and developing applications, use of mobile devices in educational contexts formal, informal and Non-informal, application of mobile technology at different levels of education, assessment of learners' outcome in m-learning environments using various key research methodologies, are key research purposes addressed in the surveyed studies. During the analysis the two types of the articles were identified that we have grouped into:

1. "Evaluation of effects in m-learning systems

2. "Design of mobile learning systems"

As it can be seen from the fig 2, most of the researches have focused on evaluating the effects of m-learning systems. The study by Y Cui et al. Hui-Chun Chu et al. implemented a knowledge engineering approach to develop mind tools for context aware ubiqutous learning, in order to evalaute the effects of $m$ learning at elementry level in Taiwan. A natural sciences course was taught using PDAs as the technological support[11].

\subsubsection{Research designs for Evaluating m- Learning Systems}

The statistics of research methodologies, as shown in fig -2 , indicate that mobile learning systems have been evaluated experimentally or by surveys only or by mixed methodologies. For example G.D. Chen et al. developed a ubiquitous learning environment for students to learn by a desktop PC, laptop, PDA and cell phone. The experiment was performed at the National Central University in Taiwan, to access the pedagogical potential and benefits of adopting the ubiquitous learning environment for integrating web-based and mobile learning. The results indicated that the testing results, task-accomplished rate and learning-goal-achieved rate can be improved by the support of the ubiquitous learning website[12]. Similarly G. Cloughet al. used survey method to investigate whether, and to what extent experienced users of mobile devices use their mobile devices to support intentional informal learning. The survey targeted PDAs and smartphone enthusiasts, who were found the most likely ones to make use of the mobile devices in informal learning[13]. The statistical analysis shows that the experimental evaluation of m-learning systems has proved to be more successful, as compared to the surveys/experiments or just survey methods alone. The Fig - 2 shows that the experimental methods for evaluation and designing of mobile learning systems have received a higher number of citations over the decade, whilst the survey and experiments, or survey, are cited lower.

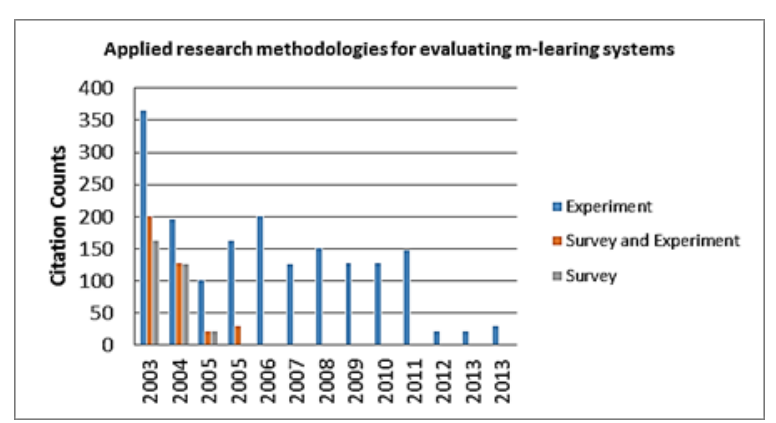

Fig 2- Research methodologies for evaluating m-learning systems

\subsubsection{Research outcomes}

Almost all the selected studies have reported positive research outcomes, while only few have reported some problem in mobile device handling and expenditure incurred on the devices. Learners are reluctant to invest time and money in personalizing and extending them, therefore ownership of the technology is clearly important [14]. On the otherhand, the mobile devices with higher specifications are also likely to increase their usage in educational contexts.

\subsection{Current technologies}

Mobile technologies have significantly penetrated into societies in a very short period of time. These technologies mainly refer to Notebooks, iPods, MP4 Players, PDAs, Tablets and smartphones. The advent of these technologies has inspired considerable interest amongst the educational community. These devices have changed the pattern of learning or work activity due to their portability and support for ubiquitous access to resources. PDAs, Handheld, Pocket PC, Smartphones, PDA Mobile Phones, notebooks are the most commonly used devices in m-learning environments. In the given below figure (Fig - 3), it can be seen that the PDAs have been the mostly used in educational and learning contexts. Smartphones are the currently used devices which most higher and post-secondary educational institutions have adopted to provide support to the ubiquitous learning. These mobile devices can be examined in terms of efficiency of instruction, student satisfaction and acceptance, and learning outcomes [15].

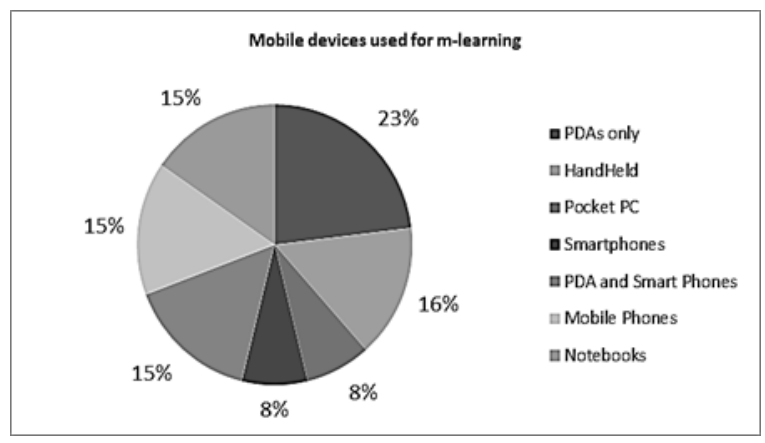

Fig 4- Mobile devices used for m-learning

\subsubsection{Mobile devices in educational contexts}

Mobile learning has been implemented in various educational contexts categorized as Formal, Informal and Non-formal

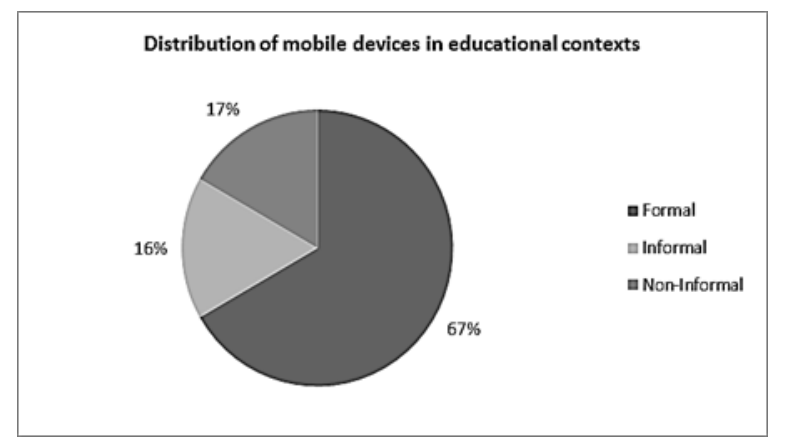

Fig 3- Distribution of mobile devices in educational contexts 
educational contexts. According to Sharples et al, the nature of m-learning extends the limits of formal education to informal learning context [16]. Therefore, informal learning experiences could be supported by m-learning as well. The results identified from the studies, shows that the mobile device distribution is $17 \%$ in the Formal, $16 \%$ in Informal and $67 \%$ in Non-informal educational contexts. The frequency of mobile device usage is found to be higher in Non-informal educational contexts as compared to formal and informal educational contexts.

\subsubsection{Technology Distribution in Educational Disciplines}

In this study, we identified various courses where m-learning applications offer varied benefits for learning at all levels. For example Gustavo Zurita, in a constructivist mobile learning environment, implemented handheld devices for teaching syllables and words to first-grade students in formal educational system [17]. A formal implementation of the cutting edge mobile learning system in a blended English classroom of 1000 students (with 800 being online), as reported by Minjuan Wang, reveals that m-learning activities better engages students' in the learning process, from passive learners to truly engaged learners who are behaviorally, intellectually and emotionally involved in their learning tasks [18]. Nuray Gedik, highlighted important issues in designing a cellular phone-based m-learning instruction as a support to $\mathrm{f} 2 \mathrm{f}$ instruction. The findings by Nuray reveal that m-learning can be considered to be more suitable for supporting f2f instruction unless a strong rationale exists to use it for other purposes [19].

\subsubsection{Mobile Device Network Access Modes}

The access to mobile services through handheld smart devices enables ubiquitous access in m-learning platforms. The number of learners in an m-learning environment can be huge and accessing data in real time may require having networks feasible for real time operation. Typically, ways of accessing networks is by means of Wi-Fi. Findings in the study reveal that the delivery of content is made available to a learner, by means of wireless networks using WAP, has proved to be an efficient and cost effective network access approach. For example Dan Corlett, discovered the patterns of use of mobile learning organizer (wireless Pocket PC with appropriate and useful software installed) used by the students in a wireless networked study environment. The study focused on identifying the most-used tools for such a learning device and their patterns and problems of usage [20].

\subsection{Distribution of Articles' by Citations}

Thirteen articles with the highest citation counts in different research purposes were selected for analysis. Out of those thirteen articles eight reported on "evaluating the effects of mobile learning" and five discussed on "mobile learning design methodologies". The citation counts for eight articles on "evaluating the effects of mobile learning", range from 23 to 365 and for the five articles focusing on "mobile learning design methodologies", have 30 to 196, as shown in Fig - 3 . Chen et al, developed mobile learning system for scaffolding bird watching learning, receives the highest citation count of 365 and focuses on evaluation of m-learning systems. Chen explored the possible roles and scaffolding aids and investigated whether student learning benefited from the mobility, portability, and individualization of the mobile[21]. C. Markett a et al. on the next level, receives the citation count of 201, for the designing a mobile learning system that used SMS service to encourage interactivity among students in the classrooms[22]. Moreover, three recent studies with $30,23,23$ citations for the articles by Han-Yu Sung et al [23], Nuray Gedik[16], Ann C. Jones et al [24] respectively, could be expected to have high citation counts in the future publications. Finally, Evaluations of m-learning systems category receive the highest citations.

\section{DISCUSSION}

Evaluating the performance of mobile devices for use in educational perspective for instruction and training is the current research trend in educational research today. This study provides important results and new findings. In this study, evaluations of mobile learning systems and their design were found to be the key research trends in mobile learning domain. For the evaluation of a mobile learning framework designs, our findings reveal that the experimental research design methods are the most efficient research methods. With $38 \%$ research studies focusing on design and $62 \%$ on the evaluation of m-learning system, the results show that more research work needs to be done in the design of efficient frameworks for m-learning system. For the effective design of mobile learning systems there is a need for an appropriate management of courses, preparation of self-study educational materials, and design of educational modules, which are accessible to the various devices.

Almost all the selected studies have reported positive research outcomes, while only few have reported some problem in mobile device handling and expenditure incurred on the devices.

Smart devices around the globe communicating through instant messages (IM) are the latest trend in M-Learning, where learners and educators can connect or access to each other in both formal as well as informal learning environment. PDAs, handhelds are currently the most widely used devices for mobile learning, but these are expected to be replaced by emerging technologies. The content delivery through WAP has proved to be an efficient and cost effective solution in $\mathrm{m}$ learning. An evaluation of m-learning systems is the category receiving the number of highest citations, indicating that the area focusing on the design of m-learning needs to be explored further.

\section{CONCLUSION}

With the rapid innovation in mobile technologies, their implementation in teaching and learning process is gaining wider acceptance at global level. The support provided by the emerging mobile technologies allows fast information exchange and processing. The efficiency of these innovations significantly increases the level of freedom for work and study, permitting anywhere anytime learning environment. Educators are in search for exploiting the unique abilities and features of these mobile technologies to create new and efficient forms of learning. Context as a central construct allows connecting learning across contexts and life transitions, and bridges gaps between the formal and informal learning [25]. This study is a systematic review of studies published from the year 2003 to 2014. The study highlights current trends in mobile learning and identifies the key research areas that need to be explored further. The findings of this study are summarized below-

- The key research areas in m-learning are the "Evaluation of m-learning systems" and "Design of mobile learning systems.

- Experimental research is found to be the primary research method in almost all the studies. 
- PDAs, handhelds are currently the most widely used devices for mobile learning, but these are expected to be replaced by emerging technologies.

- The implementation of m-learning is found to be higher in higher educational levels then elementary levels

- When implemented in educational environments, mlearning systems have produced positive outcomes.

- Evaluation of m-learning systems is the category receiving the highest number citations

\section{REFERENCES}

[1] M. Sharples, "The design of personal mobile technologies for lifelong learning," Comput. Educ., vol. 34, no. 3-4, pp. 177-193, Apr. 2000.

[2] A. Kukulska-Hulme, J. Pettit, L. Bradley, A. a. Carvalho, A. Herrington, D. M. Kennedy, and A. Walker, "Mature Students Using Mobile Devices in Life and Learning," Int. J. Mob. Blended Learn., vol. 3, no. 1, pp. 18-52, 2011.

[3] P. Dulev, "The use of tablets as mobile aids in Elearning," Proc. Int. Conf. - New Horizons Educ. , Port., 2011.

[4] W.-H. Wu, Y.-C. Jim Wu, C.-Y. Chen, H.-Y. Kao, C.-H. Lin, and S.-H. Huang, "Review of trends from mobile learning studies: A meta-analysis," Comput. Educ., vol. 59, no. 2, pp. 817-827, Sep. 2012.

[5] K. Melhuish and G. Falloon, "Melhuish, K. \& Falloon, G. (2010). Looking to the future: M-learning with the iPad.," vol. 22, pp. 1-16, 2010.

[6] G. Hwang and H. Chang, "Computers \& Education A formative assessment-based mobile learning approach to improving the learning attitudes and achievements of students," Comput. Educ., vol. 56, no. 4, pp. 1023-1031, 2011.

[7] S. Liaw, M. Hatala, and H. Huang, "Computers \& Education Investigating acceptance toward mobile learning to assist individual knowledge management: Based on activity theory approach," vol. 54, pp. 446454, 2010.

[8] D. Shin, Y. Shin, H. Choo, and K. Beom, "Computers in Human Behavior Smartphones as smart pedagogical tools: Implications for smartphones as u-learning devices," Comput. Human Behav., vol. 27, no. 6, pp. 2207-2214, 2011.

[9] J. Da Bormida, G., Bo, G., Lefrere, P., \& Taylor, "An Open Abstract Framework for Modeling Interoperability of Mobile Learning Services," Eur. J. Eng. Inf. Soc. Appl., vol. 5, no. 1, 2003.

[10] C.-K. Looi, P. Seow, B. Zhang, H.-J. So, W. Chen, and L.-H. Wong, "Leveraging mobile technology for sustainable seamless learning: a research agenda," Br. J. Educ. Technol., vol. 41, no. 2, pp. 154-169, Mar. 2010.

[11] H. Chu, G. Hwang, and C. Tsai, "Computers \& Education A knowledge engineering approach to developing mindtools for context-aware ubiquitous learning," Comput. Educ., vol. 54, no. 1, pp. 289-297, 2010.

[12] G. D. Chen, C. K. Chang, and C. Y. Wang, "Ubiquitous learning website: Scaffold learners by mobile devices with information-aware techniques," vol. 50, pp. 77-90, 2008.

[13] G. Clough, A. C. Jones, P. Mcandrew, and E. Scanlon, "Informal learning with PDAs and smartphones," pp 359-371, 2008.

[14] D. Corlett, M. Sharples, S. Bull, and T. Chan, "Evaluation of a mobile learning organiser for university students," pp. 162-170, 2005.

[15] N. Gedik, A. Hanci-Karademirci, E. Kursun, and K. Cagiltay, "Key instructional design issues in a cellular phone-based mobile learning project," Comput. Educ. vol. 58, pp. 1149-1159, 2012.

[16] N. Gedik, A. Hanci-Karademirci, E. Kursun, and K. Cagiltay, "Key instructional design issues in a cellular phone-based mobile learning project," Comput. Educ., vol. 58, no. 4, pp. 1149-1159, May 2012.

[17] G. Z. Ã and M. Nussbaum, "A constructivist mobile learning environment supported by a wireless handheld network," pp. 235-243, 2004

[18] M. Wang, R. Shen, D. Novak, and X. Pan, "blended classroom," vol. 40, no. 4, pp. 673-695, 2009.

[19] N. Gedik, A. Hanci-karademirci, E. Kursun, and K Cagiltay, "Computers \& Education Key instructional design issues in a cellular phone-based mobile learning project," Comput. Educ., vol. 58, no. 4, pp. 1149-1159, 2012.

[20] D. Corlett, M. Sharples, S. Bull, and T. Chan, "Evaluation of a mobile learning organiser for university students," J. Comput. Assist. Learn., vol. 21, no. 3, pp. 162-170, May 2005

[21] Y. S. Chen, T. C. Kao, and J. P. Sheu, "A mobile learning system for scaffolding bird watching learning," no. April, pp. 347-359, 2003

[22] C. Markett, I. A. Sánchez, S. Weber, and B. Tangney, "Using short message service to encourage interactivity in the classroom," Comput. Educ., vol. 46, no. 3, pp. 280-293, Apr. 2006.

[23] H.-Y. Sung and G.-J. Hwang, "A collaborative gamebased learning approach to improving students' learning performance in science courses," Comput. Educ., vol. 63, pp. 43-51, Apr. 2013.

[24] A. C. Jones, E. Scanlon, and G. Clough, "Computers \& Education Mobile learning: Two case studies of supporting inquiry learning in informal and semiformal settings," Comput. Educ., vol. 61, pp. 21-32, 2013.

[25] J. Article, "Innovation in Mobile Learning: A European Perspec- tive," 2009 